Fanum

Sociológico

\section{Forum Sociológico}

Série II

23 | 2013

Número 23

\title{
Processos no tempo: uma reflexão sobre o valor que a história acrescenta à sociologia, a partir do magistério de Vitorino Magalhães Godinho
}

\section{Augusto Santos Silva}

\section{OpenEdition}

Journals

Edição electrónica

URL: https://journals.openedition.org/sociologico/848

DOI: $10.4000 /$ sociologico.848

ISSN: 2182-7427

Editora

CICS.NOVA - Centro Interdisciplinar de Ciências Sociais da Universidade Nova de Lisboa

Edição impressa

Data de publição: 1 novembro 2013

ISSN: 0872-8380

Refêrencia eletrónica

Augusto Santos Silva, «Processos no tempo: uma reflexão sobre o valor que a história acrescenta à sociologia, a partir do magistério de Vitorino Magalhães Godinho», Forum Sociológico [Online], 23| 2013, posto online no dia 01 janeiro 2014, consultado o 31 março 2022. URL: http://

journals.openedition.org/sociologico/848; DOI: https://doi.org/10.4000/sociologico.848

Este documento foi criado de forma automática no dia 31 março 2022.

(C) CICS.NOVA 


\title{
Processos no tempo: uma reflexão sobre o valor que a história acrescenta à sociologia, a partir do magistério de Vitorino Magalhães Godinho
}

\author{
Augusto Santos Silva
}

\section{A “história intrinsecamente sociológica"}

1 No último texto que reviu - e foi publicado já em edição póstuma - Vitorino Magalhães Godinho escreveu: "Não há oposição entre História e Sociologia, tão-só, se quisermos, o contraste entre sublinhar os processos ou as estruturas: a maior atenção às mudanças quanto aos primeiros, às permanências nas segundas." Para precisar, logo na frase seguinte: "Mas até este contraste é superficial, ou melhor, só pode ser operatório." E concluir: "A história é intrinsecamente sociológica, a sua trama é tecida pelas estruturas e processos" (Godinho, 2011: 25, 160).

Quero considerar as condições do diálogo entre estas ciências, a partir das lições de Magalhães Godinho. Entenda-se bem: não se trata de sumariar tais lições, nem de fazer delas caução para a minha maneira de conceber o diálogo. Trata-se, sim, de defender que os dois movimentos combinados que, ao longo de todo o seu magistério, Vitorino Magalhães Godinho não se cansou de defender, constituem focos poderosíssimos para iluminá-lo. Designá-los-ei, à minha exclusiva responsabilidade, como um movimento de sociologização da história e um movimento de historicização da sociologia.

Ou, dito de outra maneira: a sociologia tem muito a beneficiar da história, sob condição de a história se conceber a si própria como uma ciência social. Ou ainda, posta a questão sob forma de pergunta: que contributos pode a história, a história que Magalhães Godinho nos ensinou a cultivar, oferecer à sociologia? 
4 Para responder, é imprescindível começar por caracterizar essa "história intrinsecamente sociológica" de que falava o mestre. Fá-lo-ei resumidamente, acentuando três aspetos fundamentais.

O primeiro é a prática da história como ciência. Isto significa problematizar, quer dizer, colocar sistematicamente questões acerca da realidade e delas partir para a definição de problemas e a construção de objetos de estudo empírico. Significa usar de método para delinear os planos e os procedimentos de observação, obter e organizar a informação de maneira integrada e coerente, identificar as regularidades e os seus padrões. Significa ambicionar a explicação dos factos, através da elaboração de teorias consistentes e sujeitáveis a prova, ou seja, ao escrutínio público disciplinar. Significa ir acumulando conhecimento, sempre no modo da problematização, fazendo dos resultados de uma investigação pontos de partida para novas questões, num processo contínuo mas cumulativo, isto é, no tempo médio e longo do desenvolvimento científico, progressivo.

O segundo aspeto é o programa - a vontade e a sua concretização - da plena integração da história, como ciência, no universo das ciências sociais e humanas. o que implica, desde logo, uma consciência clara das razões da pertença a tal universo; e, subsequentemente, o cultivo das relações de vizinhança com a geografia, a economia, a psicologia, a sociologia, a antropologia, a semiologia e a linguística, em interação diádica ou em campos multidisciplinares (como as ciências jurídicas, políticas, da linguagem e da comunicação, da gestão, etc.).

7 O que por sua vez requer - último aspeto a destacar - a compreensão de que as ciências sociais e humanas não se diferenciam por especializações empíricas (esta "realidade" para mim, aquela para ti), mas sim pelas diferentes perspetivas que acionam e iluminam dimensões distintas dos mesmos factos, processos ou estruturas. Como insistia Godinho, lembrando a atualidade da ideia de Marcel Mauss, as "condutas humanas" e as estruturas que as moldam representam "totalidades", que pedem a concorrência de várias perspetivas, vários "eixos" de problematização (Godinho, 2011: 127-129), para ganharem inteligibilidade. É, por conseguinte, um erro pensar que exista um homo oeconomicus distinto do homo sociologicus ou do homo psicologicus; existem, isso sim, várias e diferentes maneiras de pensar e interpretar a ação humana, os seus resultados e as suas circunstâncias. Ora, neste quadro, o que a história problematiza é o tempo, a inscrição das sociedades no tempo, e esse é o valor que acrescenta, como "maneira de pensar" as sociedades - e, assim, como maneira de pensar também as restantes ciências sociais.

8 A conceção da história como ciência social encontra-se bastante longe de entendimentos que já tiveram os seus momentos de fortuna entre os especialistas e as instituições académicas, ou estão a tê-los precisamente agora. Sejamos claros, sem medo da polémica: a redução da historiografia à reconstituição de sequências de factos, seja ela austeramente subordinada aos cânones da erudição ou aventure-se como narrativa mais ou menos literária e mais ou menos imaginosa, e tempere-a ou não a inclusão tempestiva de descrições de ambiente, retratos psicológicos ou mesmo recriações de estados de alma, não aproxima, bem pelo contrário, afasta a história das regras e da prática das ciências sociais (independentemente do alcance próprio da descrição e da narração, como elementos de explicação, a que adiante regressaremos). E outro tanto acontece com essas tendências da moda, para - tendo em vista potenciar o sucesso comercial ou a influência política - transformar a história numa espécie de 
reportagem jornalística retrospetiva, ou numa série mais ou menos coerente de comparações e juízos anacrónicos.

É, portanto, sob condição de assumir plenamente a natureza de ciência social - ser “intrinsecamente sociológica”, como escreveu Magalhães Godinho - que a história pode acrescentar valor ao universo das ciências sociais. Mas, cumprida essa condição (e aceites as respetivas consequências, quanto a menor capacidade de excitar emoções, prender leitores ou fornecer ditos espirituosos a jornalistas, comentaristas e atores políticos), são fecundas, ao que creio, as contribuições que pode fazer.

Com mais preocupações de exemplificação do que de exaustividade, identificarei essas contribuições em cinco planos: a construção da problemática; a metodologia; a modelização; a epistemologia; e a comunicação pública. Seguirei uma ordem que pode surpreender um leitor ou leitora formados a partir da sociologia, mas que, como se verá, faz sentido numa abordagem que provém da perspetiva e da história teórica e institucional da ciência histórica.

\section{Questões de problematização}

11 Assim, e em primeiro lugar, o trabalho de problematização. Evidentemente, a contribuição maior da história é a colocação dos processos sociais no eixo do tempo, isto é, a integração da variável "tempo" no centro da nossa indagação.

$\mathrm{O}$ que confere à problematização sociológica uma perspetiva em profundidade que, de outro modo, manifestamente não possui - e a capacidade de reter a espessura, a densidade das estruturas sociais que se vão consolidando ao longo da duração. Esta ideia de que os factos (no sentido geral de fenómenos, não no sentido restrito de eventos singulares) têm uma história, se formam numa dimensão temporal, de extensão variável, mas que é preciso conhecer para compreender a sua consistência, a sua inércia, a sua configuração - deve ser um princípio básico do trabalho daquele que analisa a contemporaneidade, seja ele, aliás, sociólogo, economista, geógrafo ou antropólogo.

13 Mas isto significa não apenas situar as sociedades humanas na permanência - nos grandes movimentos de enraizamento e cristalização, decenais, seculares ou milenares - mas também, e talvez sobretudo, situá-las no devir. A evolução não é somente consolidação, é ainda variação. A temporalidade dos processos sociais ilumina os vetores da sua transformação, bem como os diferentes ritmos das mudanças diferentes consoante a natureza dos processos, consoante os contextos que os envolvem, consoante as estruturas implicadas.

14 Trata-se, pois, de explorar a tensão entre permanência e mudança, entre identidade e alteração, entre reprodução e transformação. E, se digo que a atenção ao tempo talvez signifique enfatizar mais o devir do que a permanência, é porque é nos sociólogos que desvalorizam a historicidade do que estudam que menos disponibilidade encontro para compreenderem a variabilidade do que estudam.

No plano da problematização, que é o que agora autonomizamos - no plano das perguntas, não ainda no das respostas -, esta tensão positiva introduzida pela consideração do eixo do tempo pode gerar ganhos consideráveis de inteligibilidade. Por uma razão simples: porque força o sociólogo à genealogia e à comparação. 
16 A abordagem genealógica explora a profundidade dos factos sociais que considera: sendo sociológica, parte do presente e percorre as escalas de tempo na medida estritamente indispensável para perceber como se formaram e desenvolveram esses factos. Faz, pois, um movimento de frente para trás, na diacronia, um movimento que se desdobra em tantos quantos os necessários para dar conta da diversidade de fatores associados a essa formação e a esse desenvolvimento.

17 A abordagem comparativa tem por axioma a afirmação de que nenhuma interpretação de um dado processo fica plenamente (sequer!) esboçada se o não contrastar com processos relacionáveis, que ocorreram ou ocorrem noutros contextos espáciotemporais. É, portanto, um gesto de alargamento do horizonte observado, para buscar, por vezes bem longe na distância, casos comparáveis, isto é, casos diferentes partilhando certas caraterísticas comuns, cuja relevância é logicamente definida pelos problemas científicos em dilucidação.

18 As duas abordagens (ou "métodos", se quisermos falar assim, mas o primeiro nome é mais preciso), genealogia e comparação, são muito úteis para quem procurar alcandorar-se ao patamar da explicação - porque contribuem poderosamente para esclarecer a dialética entre o geral e o singular, entre o que tem de específico um determinado processo e o que nele remete para atributos extensivos a uma dada classe de processos.

Não lograremos, contudo, enriquecer a problemática sociológica por via da consideração da variável tempo se tivermos, desta, um entendimento mecanicista.

O tempo não é apenas um parâmetro. $O$ tempo não pode ser reduzido a uma espécie de variável independente. $O$ tempo é um quadro em que decorre uma experiência social (a experiência do mundo e do ser no mundo de cada ator e cada grupo de atores) - e, nesse sentido, é uma condição (recurso e constrangimento) dessa experiência; mas é, também, uma dimensão da experiência social - e, nesse sentido, tem um conteúdo que resulta de cada experiência social e varia com a variação do conjunto das experiências que retemos.

21 Portanto, não é possível colocar, situar a ação social no tempo sem atender ao que, em cada circunstância e em cada campo, os atores sociais definem e concebem como tempo: a temporalidade a que se referem, a duração em que se inscrevem, a si e aos outros. Os tempos que pontuam os processos sociais não são, pois, dados, ou estruturas uniformes e permanentes, antes pertencem à ordem do vivido.

Isto é particularmente importante quando ensaiamos abordagens de tipo genealógico. Investigar o passado da contemporaneidade, indagar da origem, da génese, da matriz, da formação dos processos que estudamos, relevar a espessura temporal das estruturas e das práticas sociais, considerar na pauta da diacronia os modos e as etapas do seu desenvolvimento e transformação, numa palavra, traçar-lhes a história para tornar mais inteligível o que são hoje, constitui um passo muito importante, senão mesmo indispensável, da análise sociológica. Mas, ao fazê-lo, não devemos perder de vista que estamos convocando o que, em si, é também uma construção social do presente, dinâmica como as demais. A origem e a génese de um facto não são algo que esteja "lá", no momento primordial que a história será capaz de identificar sem ambiguidade. São um ensejo de representações sociais, mais ou menos institucionalizadas, mais ou menos codificadas. A genealogia que o sociólogo consciente da historicidade dos factos cultiva há-de ser, pois, também a consideração crítica das memórias sociais, dos patrimónios e 
tradições que cada sociedade ou grupo social vai construindo, reconstruindo e transmitindo.

Depois, para os historiadores que leram e compreenderam Fernand Braudel, o tempo diz-se no plural.

Múltiplos tempos, isto é, múltiplas dimensões temporais da realidade social e diversas escalas (pautas, ritmos, durações) de referência da realidade social. Acontecimento, conjuntura, estrutura: não apenas diferentes "grandezas", extensões, dos ciclos em observação, mas sobretudo diferente pulsar, velocidade e dinamismo. Magalhães Godinho (2011: 156-157) chama justamente a atenção para que a aceleração da história tem, em geral, encurtado as durações e sugere a vantagem de pensar em termos, não de três, mas de cinco dimensões: tempo muito longo, longo, médio, breve, instantâneo.

Estes múltiplos tempos não são camadas justapostas, que pudessem ser escavadas uma após outra. Raros serão os factos sociais (se é que haverá algum) em que não verificaremos, ao contrário, o entrelaçamento dos tempos, a imbricação dos tempos: múltiplas ondas convergindo para o mesmo feixe.

Frequentemente, estes entrelaçamentos são desencontros; os tempos que, vistos numa perspetiva sincrónica, num dado momento (qualquer que seja a respetiva envergadura), parecem cruzar-se, conflituam entre si - diferentes maneiras de ser, de pensar e de agir, diferentes operadores simbólicos, diferentes rotinas incorporadas, diferentes ritmos, crenças e expectativas, quer dizer, diferentes referenciações da ação porque a referência temporal é internamente heterogénea, por vezes até inconsistente (e então temos tipicamente situações de encruzilhada). De novo Magalhães Godinho, já em 1981: “as estruturas não passam de momentos, mais ou menos longos, em processus de estruturação, desestruturação e reestruturação. Qualquer que seja o campo considerado. Nunca a simultaneidade se explica autonomamente a si própria, cada relação da parte com o todo, de elemento com o conjunto contém em si, pressupõe a relação com o que precedeu: a sincronia nada é sem a diacronia, que por seu turno é discronia, quer dizer desigualdade de desenvolvimento no tempo, distorção, atrasos ou avanços" (Godinho, 1981: 16).

Em síntese: colocar os processos no eixo do tempo é o contributo maior de uma história "intrinsecamente sociológica" à problemática sociológica. Mas isso não significa oferecer uma simples tábua cronológica onde possa ganhar coerência e sentido a sucessão. Não se trata apenas de datação. Nem de regressar à noção antiga de processo histórico, como o desenvolvimento unilinear, época a época, de um percurso, local, nacional ou universal, de que a história traçaria o rumo e a filosofia da história indagaria, hegelianamente, o sentido. Não: é mesmo questão de integrar, nos modelos de descoberta, análise e explicação, as dimensões do tempo, na sua multiplicidade e na sua variedade, como criações e como condições das práticas sociais.

\section{Questões de metodologia}

No plano metodológico, também não me oferece nenhuma dúvida a identificação do contributo principal da história à sociologia: reside no trabalho com as fontes. 0 diálogo é, aliás, muito fácil. Primeiro, porque ambas as ciências têm uma tradição robusta de análise e debate sobre as condições de produção dos "dados" para investigação empírica (tal como a antropologia, por exemplo, e bem mais do que a economia). 
Segundo, porque é claro onde se situa o potencial de ensinamento recíproco. A sociologia tem bastante a dizer aos historiadores que têm de usar métodos e técnicas de observação que produzem informação dita primária: as entrevistas, os questionários ou mesmo a observação direta a que recorrem crescentemente os especialistas de história contemporânea, de história do património, de história da cultura popular. A história tem muito a dizer aos sociólogos cuja observação é mediada pelo que os manuais qualificam como análise secundária de informação - e quase todos os sociólogos o fazem regularmente.

Concentrar-me-ei, portanto, neste segundo aspeto. Que é de cariz metodológico, e não apenas técnico, quer dizer, tem tipicamente que ver com a combinação teoricamente orientada e justificada de procedimentos de pesquisa ao mesmo tempo exequíveis e relevantes para o objeto de investigação em cada momento em causa.

A linguagem, que é, além de um instrumento essencial de comunicação, um precioso recurso para conseguirmos modular a expressão, faz também, por vezes, de falso amigo, levando a ilusões funestas. É o caso do uso da palavra "dados" - na verdade, os dados não são dados, mas sim construídos, os investigadores não são meros recoletores, à maneira dos homens anteriores à revolução agrícola do Neolítico. E ainda mais grave é a insistência (aliás, errada, do ponto de vista da língua) na palavra "evidência", para designar informação: nada há de menos evidente do que os dados construídos pela pesquisa científica; pelo contrário, essa construção implica quase sempre passar além da aparência das coisas, desconfiar das primeiras impressões, controlar tecnicamente a intuição, desvelar, desvendar, penetrar.

Ora, no caso, da chamada análise secundária de informação, a construção dos dados é sempre uma operação de segundo (ou enésimo) grau, uma metaconstrução. Porque esses dados já foram construídos socialmente, essa informação resulta de operações, mais ou menos institucionalizadas, e muitas vezes extremamente complexas, ou muito ritualizadas, conduzidas pelas comunidades humanas, as suas autoridades, os seus interesses, os seus protagonistas. A massa dos documentos administrativos que pontuam as etapas da vida individual e familiar e são preservados em arquivos públicos, as atas de funcionamento das instituições políticas, a contabilidade organizada de agentes económicos, como as torres erguidas pelas comunas burguesas, as igrejas espalhas pelo território rural ou os ícones inscritos na paisagem urbana pelas sucessivas exposições internacionais, são todos resultados e fatores de decisões e comportamentos situados no tempo, no espaço e num contexto social. Usá-los como material analítico é reconfigurá-los noutro enquadramento e para outros fins - e quem quer que o faça sem ter plena consciência deste movimento e das suas consequências nunca deles tirará pleno partido.

Os historiadores falam, e bem, de fontes para designar todos os materiais produzidos, difundidos, codificados (alterados, destruídos, reconstruídos, etc.), de que nos servimos para a construção da informação relevante para a nossa pesquisa. Esta tem na identificação, crítica e tratamento das fontes um dos seus primeiros passos lógicos. A teoria e a análise das fontes são, pois, competências indispensáveis para qualquer estudante ou especialista. Ora, o cabaz de princípios mínimos para o desenvolvimento de tais competências há de incluir os seguintes.

Do ponto de vista da teoria das fontes, a consciência de que, como escreveu Godinho (2011: 134), "todas as fontes são obras culturais (no sentido antropológico)" - sendo que o sociólogo rapidamente acrescentaria, "e sociais". Obras, primeiro: precisamente, não 
dados, não matérias-primas, antes resultados e traços - e por isso mesmo potenciais documentos - da ação humana em sociedade. Culturais, depois, envolvendo operadores intelectuais e simbólicos, essa utensilagem mental de que falava Lucien Febvre, e as crenças, os valores e as normas que os enquadram, de que os homens e as mulheres comuns, os grupos e as instituições fazem uso para agir e exprimir-se. Sociais, por último, porque o contexto em que aquilo que agora para nós é fonte foi produzido (e, ao longo do tempo, transformado) é uma condição determinante da sua materialidade e significação. Isto, que se diz que os historiadores aplicam ao passado, aplicarão os sociólogos ao presente - e, nesta altura da argumentação, já sabemos que melhor será dizer que uns e outros aplicam ao passado e podem aplicar também ao presente: aos recenseamentos demográficos, agrícolas, industriais, aos quadros de pessoal das empresas, aos jornais, rádios e televisões, aos discursos parlamentares, a lista poderia continuar indefinidamente. Mas, então, para compreender e aproveitar as fontes, é preciso fazer a teoria das fontes. Em sentido próprio: a explicação de cada fonte, a sua inserção no processo de construção de que resulta (quem a produziu, em que condições, para quê, como, com que alcance, quem a usou, de que maneira, quem a conservou, etc., etc.), e o escrutínio do seu conteúdo à luz dessa contextualização.

As consequências no plano das técnicas e métodos de análise parecem-me óbvias. Mas são tantas vezes esquecidas por sociólogos e economistas (quando não pelos próprios historiadores) que talvez valha a pena dedicar-lhes umas breves linhas.

De entrada, remeter cada fonte para o conjunto de que faça parte e em que adquira relevância e sentido. Nunca esquecer que a ciência lida com regularidades - e é aí, não fora delas, que o facto singular ganha singularidade. A análise histórica ou sociológica de fontes, históricas ou contemporâneas, é a identificação, interpretação e tratamento de conjuntos - sistemáticos ou não, mas sempre estruturados - de fontes: corpora documentais; séries cronológicas; séries estatísticas; conjuntos monumentais; sítios (como os arqueólogos falam de sítios, isto é, espaços trabalhados onde se inscrevem monumentos, habitações, utensílios, paisagens, etc.).

Depois, entender o tratamento da fonte como um duplo balanço: situá-la no conjunto que lhe serve "atualmente" de contexto, no quadro de cada investigação concreta; mas situá-la também longitudinalmente, na cadeia de factos culturais e sociais de que é o (provisório e alterável) resultado presente.

37 Finalmente, vincular sempre as operações técnicas de tratamento da informação construída a partir das fontes - o que os manuais chamam a análise dos dados - às operações técnicas dessa construção - o que se designa convencionalmente por recolha dos dados. Ponto fundamental: essas operações técnicas envolvem sempre opções e produzem sempre resultados; pois umas e outros têm de ser vinculados, não só entre si, em cada fase ("recolha" ou "tratamento"), mas entre as duas fases. Por maior que seja a sofisticação tecnológica e intelectual do tratamento, a validade científica da informação repousa sempre, em última instância, sobre a validade dos protocolos teóricometodológicos associados à construção das fontes de informação.

\section{Questões de modelização}

38 A ambição de qualquer investigação é contribuir para a teoria da ou das disciplinas científicas a que se refere. A teoria sociológica, como a teoria económica, constitui o conjunto de conhecimentos em cada momento e contexto disponíveis, quer dizer, 
aqueles que vão sendo submetidos e vão ultrapassando a prova da demonstração e do debate organizado, informam o património comum (mais ou menos concebido como cânon) e estão acessíveis para os processos de socialização e enculturação típicos de uma ciência institucionalizada (nas escolas, nos centros de investigação, nos terrenos de aplicação, no espaço público, etc.). Os historiadores são normalmente avessos a usar uma expressão tão ambiciosa, mas, do meu ponto de vista, fazem mal: no sentido aqui usado, a teoria é o ponto de partida e é o ponto de chegada do trabalho de cada cientista e o cimento agregador de cada comunidade científica.

Em nenhuma ciência, muito menos em nenhuma ciência social, é a teoria, assim concebida, uniforme. O pluralismo e o debate interno são fatores de enriquecimento desde que não signifiquem incomunicação e simples coexistência, mas sim controvérsia e construção cumulativa (cf., por todos, Pires, 2007).

Ora, a teoria compreende múltiplos níveis de abstração e generalidade. Para o que nos importa agora, convém distinguir pelo menos dois: os sistemas de proposições de elevado grau de abstração, independentemente da formalização (mas tendendo para ela), que constituem orientações para a pesquisa e para a análise empírica - a que chamarei modelos; e as explicações referenciadas a certos e determinados problemas, envolvendo a consideração de certos e determinados processos sociais - a que chamarei teorias regionais, para que se perceba como conotam coisa diferente daquela evocada pela palavra "teoria", usada no singular e sem outro adjetivo que não o da sua filiação disciplinar.

41 Não haveria espaço, neste texto, nem seria pertinente, na ocasião, estar a dissecar o valor acrescentado por variadíssimos trabalhos históricos à teoria sociológica. Reterei, isso sim, alguns contributos discerníveis no plano dos modelos de análise. E não é por qualquer gosto da provocação ou exaltação da originalidade que identificarei tais contributos em torno do conceito de estrutura. Antes por conviç̧ão: o historiador que pense que é na ênfase no acontecimento singular e irrepetível que reside a contribuição principal da sua ciência arrisca-se, no meu modesto entender, não apenas a passar ao lado do diálogo mais profícuo com a sociologia como até a equivocar-se sobre a própria história.

Carateristicamente, as achegas do labor historiográfico ao desenvolvimento da teoria de raiz sociológica sobre as estruturas sociais assumem duas formas: inovação, por um lado; corroboração, por outro.

Para mim, a inovação maior é, sem qualquer dúvida, o encaixe dos fenómenos sociais (dos factos, na acepção mais geral) nas estruturas de média, longa e muito longa duração. As lições de Fernand Braudel e da escola cujo eixo foi essa revista sintomaticamente intitulada: Annales, Économies, sociétés, civilisations. Lições preparadas, na viragem moderna da historiografia, por Marc Bloch ou Lucien Febvre, acompanhadas, no mundo anglo-saxónico, por autores como Eric Hobsbawm ou E.P. Thompson - e que convergem, por sua vez, com os estudos sociológicos de um Max Weber ou de um Norbert Elias. Os espaços (físicos e humanizados), as civilizações e as culturas materiais, os diferentes níveis de organização e dinamismo da actividade económica (desde a economia doméstica e local aos mercados e à mundialização), as instituições de reconhecimento, ocupação e administração dos territórios, as grandes linhas de organização social, as línguas, as religiões, as mentalidades - tudo isso, com esta ou outra designação, constitui um quadro, longamente amadurecido e densamente consolidado, onde se inscrevem, onde encaixam os factos sociais: as práticas, as 
estruturas e as zonas de mediação entre umas e outras que pontuam a existência social das pessoas, dos grupos e das organizações. O papel da duração no ordenamento social - na ordem social, em sentido não normativo - é a lição fundamental que o historiador pode oferecer a um sociólogo atento.

Mas isso quer então dizer que a espessura histórica de cada estrutura social está presente e ativa no presente dessa estrutura. Que a estrutura que o olhar sociológico observa é também a sua própria história, o processo da sua consolidação, sedimentação, densificação, maturação; as metáforas variam, mas todas no fundo almejam conotar a formação da estrutura como tal, isto é - e não se trata de jogar com as palavras -, a estruturação. A diacronia está presente na sincronia, o passado no presente, sendo cada coisa o que é também por causa do que foi, e do que foi/vai sendo. Tudo pensado no plural, evidentemente, já sabemos que os tempos e as estruturas são múltiplos e os seus cruzamentos tensos.

Encaixar os factos nas estruturas significa encaixá-los nos processos sociais. Como bem explica Vitorino Magalhães Godinho (2011: 51-57, 154-155), se processos e estruturas representam "as noções operatórias mais gerais", para historiadores e sociólogos, e se os historiadores tendem a acentuar instintivamente a perspetiva dos processos - isto é, da inscrição dos factos sociais no devir - ao passo que os sociólogos procedem analogamente quanto às estruturas - isto é, valorizam os padrões de regularidade, as constantes, as invariantes que atravessem diferentes situações -, trata-se, todavia, de inclinações que convergem, e daí a importância do diálogo interdisciplinar. Os processos estão muito longe de ser cadeias de acontecimentos singulares e sucessivos; as estruturas não podem ser reduzidas a realidades estáticas. A estrutura pode ser mais bem apercebida como "a tendência que as mudanças desenham, o itinerário de percurso das transformações"; "os processos lentamente configuram estruturas ou corroem-nas, ondulam em movimentos de avanços e recuo, de expansão e contração, fraturam-se em explosões súbitas ou esperadas, repondo-se a situação anterior ou colocando os alicerces de um viver diferente". "Quer dizer - continua Godinho - que estruturas e processos são interconexos, não podemos compreender umas sem os outros e reciprocamente. No in-texto dos múltiplos espaços-tempos" - e repare-se como o autor força a linguagem para que não fique nenhum equívoco sobre o papel conformador do espaço-tempo (que não é apenas um contexto, mas por assim dizer o núcleo essencial do próprio texto).

Encaixe dos factos nas estruturas e destas na duração; presença da diacronia na sincronia - e, portanto, operacionalidade da abordagem genealógica, a que procede de frente para trás no eixo do tempo; interconexão das estruturas e dos processos sociais: eis, pois, o que se deve caraterizar plenamente como inovações conceptuais, que a história pode e deve trazer à sociologia.

Mas o historiador treinado na dilucidação de estruturas de diversa configuração sejam elas os quadros demográficos e materiais da vida quotidiana, as instituições sociais da economia, as mentalidades, os cenários geoestratégicos de interação das grandes potências, etc. - está bem habilitado para a assunção plena de certos princípios da análise sociológica. É caso então para falar, no que toca ao seu valor acrescentado, não de inovação, mas de corroboração. Duas corroborações me parecem especialmente relevantes.

48 A primeira é a confirmação, em sede de investigação histórica, da objetividade das estruturas sociais. Como ensinam várias correntes sociológicas, mas sem o consenso 
universal da disciplina, antes continuando a motivar acesas controvérsias, as estruturas não têm certamente uma realidade substantiva própria: não são atores como as pessoas o são e, pese embora as facilidades de expressão ou liberdades de estilo, não têm atributos pessoais, como sentimentos, emoções e outras disposições do género. Não são, em suma, antropomorfizáveis. Elas existem em função da ação concreta de concretos seres em relação: são resultado, condicionamento e recurso de tal ação. Dito isto, existem: são realidades objetivas, dotadas de propriedades emergentes de si mesmas, são transcendentes a cada ator e a cada ação e às diversíssimas configurações circunstanciais de ações e atores. Um Estado, uma classe social, uma confissão e uma organização religiosa, um regime demográfico, um corpo militar, uma profissão, um município, um sistema técnico, um conjunto de regras sociais, tudo isso tem uma presença social própria, objetiva embora não substancial, uma inércia e um impacto discernível, que faz agir os indivíduos, os grupos e as sociedades. Não é a pura agregação conjuntural das decisões e comportamentos individuais, pretendida por todas as variantes do atomismo.

49 A segunda confirmação respeita à conceptualização da relação entre estrutura e ação. Os sociólogos não experimentam dificuldade em explicar que a estrutura representa um condicionamento exterior à ação - por exemplo, as limitações que os mercados de produtos e serviços colocam à iniciativa de cada empresário ou grupo de empresários. Mas já se passa coisa diferente quando se trata de mostrar que a estrutura gera a ação porque é internalizada nela - basta que nem todos os sociólogos aceitam esta proposição. E, contudo, qualquer especialista ou simples estudante da história das mentalidades o compreende bem - porque, precisamente, está há muito habituado (desde pelo menos o estudo fundador de Lucien Febvre sobre as condições da descrença no século XVI, a propósito de Rabelais) a ver como as maneiras de ser, pensar e agir coletivamente forjadas e difundidas, nas diferentes épocas e espaços, moldam tão decisivamente os comportamentos individuais e grupais. Moldam por assim dizer por dentro, isto é, enquanto são assumidos e interiorizados como o sistema de perceção e apreciação próprio de cada ator. Durante bastante tempo, os historiadores ignoraram o conceito de habitus, proposto por Pierre Bourdieu, para dar conta deste processo de incorporação (também em sentido literal) da estrutura. Porém, a muitos sucedia o mesmo que a M. Jourdain, le bourgeois gentilhomme de Molière: fazer prosa sem reparar...

\section{Questões de epistemologia}

A epistemologia é o conhecimento sobre o conhecimento científico - uma reflexão organizada sobre as condições de produção e validação do conhecimento científico. Neste plano, a história pode ajudar bastante a sociologia a avançar em duas questões recorrentes: a relação entre o geral e o singular, do ponto de vista do alcance das teorias; e a relação entre o descritivo e o explicativo, do ponto de vista da inteligibilidade dos factos.

51 Uma das ideias fundamentais de Max Weber é que as ciências sociais são ciências culturais e históricas. Culturais, porque a interpretação de tudo o que envolve a ação dos homens e das mulheres requer uma mediação através do sentido que os homens e as mulheres atribuem ao que fazem. Históricas, porque esta mesma caraterística distintiva do comportamento humano face a outros tipos de comportamento confere uma natureza indireta, mediada, a todo o conhecimento que o considera - e um 
contorno singular, referido a uma constelação em concreto, como tal única, à teoria que procura explicá-lo (para maior desenvolvimento, cf. Silva, 1988).

Esta ideia parece-me profundamente atual. Mas ela deve contribuir para superar falsas oposições.

Em primeiro lugar, o alcance regional ou local (uso metaforicamente estas marcações geográficas) das explicações histórico-sociológicas em nada impede ou perturba o não menos indispensável trabalho de modelização. Precisamos é de compreender que o modelo de análise não é o fim último, mas um instrumento da investigação. Sob pena de o descarnarmos até ao ponto de ficar vazio, o modelo deve ser permanentemente sujeito à prova da confrontação com configurações de variáveis concretas, por aí singulares, no duplo sentido de específicas e irrepetíveis. A bem dizer, a explicação propriamente dita vincula-se à singularidade: à singularidade do problema ou problemas que tomou por linha condutora, à singularidade do objeto que a propósito dele ou deles definiu, à singularidade do plano de observação (em sentido amplo, da pesquisa empírica) que a propósito dele delineou e do modo de abordagem que assim praticou. A consciência esclarecida desta natureza, que o trabalho do historiador tanto favorece, é um bom antídoto contra os excessos de formalismo, risco sempre presente em ciências como a sociologia e a economia. Porque é também a consciência de uma verdade lógica elementar, tantas vezes esquecida: a máxima abstração (a máxima abstração, que abstrair é intrínseco ao esforço intelectual) maximiza a generalidade mas minimiza a densidade. A solução não está, pois, em escolher um ou outro rumo, mas sim em combinar os dois - num movimento de vaivém entre o modelo e, diria Robert Merton, a teoria de médio alcance, entre as leis gerais e as explicações contingentes (no sentido de vinculadas a circunstâncias específicas), entre o conhecimento global e o "conhecimento local".

A expressão entre aspas pertence não a um historiador, mas a um antropólogo, bem ciente da confluência das maneiras de pensar nas ciências humanas. Falo de Clifford Geertz, que é, do meu limitado ângulo de visão, quem melhor acentua a importância daquele movimento, sem nunca perder de vista que se trata de um movimento interno à teoria, isto é, a um dado nível de abstração e generalidade. Esse é o ponto: usando e testando modelos em explicações indexadas a singularidades, e procurando inferir destas explicações proposições que possam robustecer e desenvolver modelos de maior generalidade, estamos sempre a fazer ciência, o que quer dizer, estamos a generalizar. Cumprindo, diz expressivamente Geertz (1983: 176), “a tarefa do artífice, de ver princípios gerais em factos paroquiais".

Estamos a "generalizar não "através dos casos, mas [a] generalizar dentro deles" (Geertz, 1978: 36), estamos a "generalizar em profundidade" (Silva, 1994: 71-74). Ambas as fórmulas vão ao limite da coerência lógica, para sublinhar que, historiador ou sociólogo, o cientista lida com os problemas que ele próprio definiu por referência à problemática de que partiu; e os problemas remetem para modalidades de relação entre factos cuja elucidação implica descer ao específico de cada configuração dos factos e dos seus contextos. Não para ignorar as tipologias gerais que organizam aquelas modalidades, pelo contrário, para as aplicar. Não para ficar aí, na irredutível concretude de cada empiria, mas para iluminar além dela, corroborando ou reconstruindo as tipologias - de forma que as tipologias agora trabalhadas possam servir, por sua vez, de hipóteses de análise e interpretação na consideração de outras concretas empirias (e assim sucessivamente). 

puxa a explicação da generalidade para a especificidade singular e contingente. Pelo contrário: não só a generalidade está sempre presente, por maior que seja a excecionalidade do caso considerado (mesmo, por exemplo, na obra do génio artístico); como, pelas razões que já abundantemente vimos, a história, na medida em que encaixa os factos no tempo, na medida em que trata os factos como processos e na medida em que estimula as abordagens genealógicas (buscando o passado do caso contemporâneo, isto é, a sua formação e desenvolvimento) e comparativas (contrastando sistematicamente diferentes casos, de diferentes contextos, relacionáveis em diferentes dimensões), a história constitui um poderoso recurso para os esforços científicos de interpretação por generalização. factos. É habitual contrapor-se, mesmo na mais sofisticada ciência social, o que é explicativo e o que é descritivo. Explicar seria dar conta de certos factos identificando as causas de que procedem, as finalidades que (sendo comportamentos individuais) prosseguem, ou as regularidades em que se inscrevem. Descrever seria só reconstituir esses factos numa linguagem própria (dos auditórios a que são reportados), sistematizando-os e tornando compreensíveis os seus conteúdos - renunciando, pois, a explicá-los.

58 Ora bem: a história "intrinsecamente sociológica" evidencia duas coisas muito importantes.

59 Uma é que, estando em causa encadeamentos de situações ou eventos no tempo, a narrativa é indispensável à sua plena inteleção. Há certamente, já o vimos, várias formas de encadeamento, não redutíveis apenas à sucessão linear - mas não será preciso invocar a literatura para recordar que há também várias formas de narrativa, não estamos limitados à ordenação linear. Nas ciências sociais, que todas lidam mais ou menos diretamente com o tempo, descrever é também narrar. Isto é, ter em conta o elemento dinâmico das realidades sociais.

Depois, descrição e narração são ambas imprescindíveis à explicação - e, designadamente, à versão mais forte da explicação, a explicação causal. Quem quiser ficar-se por proposições de natureza teleológica ou pela subsunção do caso na regularidade a que pertença pode talvez dispensar (é uma concessão que faço, por razões de brevidade na argumentação) a caraterização substantiva dos factos sociais que considera. Mas, como escreveu Boaventura de Sousa Santos (1988), "«o quê» do acontecer só é suscetível de explicação enquanto «como» do acontecer". É também isto que pedimos ao saber especializado: que nos dê a conhecer diversas realidades, na própria riqueza e complexidade de cada uma, para que assim possamos compreendê-las melhor (e, por aí, compreender melhor quer a própria realidade em que vivemos, quer aquela que projetamos).

61 A história está muito longe de ser apenas, ou sobretudo, narrativa. A explicação densifica e esclarece a descrição e a narração. Mas, pelo menos nas ciências sociais e humanas, a explicação compreende, integra a descrição e a narração - exactamente porque procura tornar inteligível a ação humana, deve interpretar e restituir os seus conteúdos significantes e deve situá-la nesse devir que, afinal de contas, resulta do agir. 


\section{Questões de comunicação}

62 A história pode contribuir para a teoria e a investigação sociológica, em múltiplos planos e de várias maneiras. Aliás, virtualmente em todos os planos relevantes para a produção científica - a construção disciplinar da problemática e do objeto de estudo, o desenho metodológico, a elaboração teórica; e incluindo a vertente, não menos importante, da reflexão epistemológica do cientista sobre as condições e os resultados do seu labor.

63 Estes contributos decorrem, em encadeamento lógico, de um ponto de partida - uma perspetiva, um foco que ilumina de certa maneira as realidades sociais. É a atenção ao tempo, a consideração do tempo como variável-chave (independente e dependente) da conformação dessas realidades. 0 que quer dizer colocá-las, situá-las a elas na duração nas estruturas e nos processos, ou melhor é dizer, como Magalhães Godinho, na "interconexão de estruturas e processos" que se alongam no tempo. Fazendo-o, logo ressaltam certas orientações básicas para a pesquisa social: o encaixe dos factos (eventos ou rotinas, atitudes ou comportamentos, atributos pessoais ou padrões grupais, etc.) no espaço-tempo, no quadro espácio-temporal que lhes serve de contexto (e "in-texto") estrutural; a dilucidação da tensão, do jogo entre reprodução e mudança, continuidade e transformação; a relevação da espessura e da densidade histórica das estruturas da nossa contemporaneidade; a assunção da natureza situada, sociocultural, dos produtos da ação e da criação humana que usamos agora como vestígios, traços, testemunhos, cartas de marear do nosso olhar, e tratamos como fontes; a indexação fundamental de cada explicação ao conjunto de factos que isola e sonda, em si mesmo singular.

A história só é capaz de oferecer (ou corroborar) estes contributos sob duas condições.

A primeira é entender o tempo, a duração, não como um dado, mas como um problema. Não como uma datação na cronologia, não como uma diacronia que organizaria a narração e a explicação causal por sequenciação linear de acontecimentos, mas como um quadro social: uma matéria plástica que as sociedades moldam, um feixe de múltiplos ritmos e pulsações, várias escalas, várias pautas condutoras da ação de cada ator. Tempos, no plural - encontros e desencontros de tempos.

E a segunda condição é entender-se a história a si própria como uma ciência social plena, plenamente integrada no universo das ciências sociais e particularmente próxima da sociologia, quando retém sociedades complexas (e da antropologia, quando retém sociedades elementares ou nichos específicos das sociedades complexas).

Os contributos apenas fazem sentido, portanto, numa relação dialogal. Uma disciplina acrescenta valor à outra de que recebe também valor. Primado da contaminação sobre a estanquidade, primado da travessia sobre a fronteira. Não se trata, bem entendido, de rasurar as diferenças, apagar as marcas e os limites, diluir as disciplinas - a última pessoa a poder embarcar nessa aventura sem retorno seria, aliás, o historiador, porque ele deve aplicar às próprias ciências o que sabe sobre a importância dos processos evolutivos para a configuração atual das coisas. E, se é a ciência social a coisa a considerar, então é mister compreender que cada uma é hoje, também, o que a tradição teórica, a institucionalização académica, o ensino especializado, o percurso no campo científico, lhe determinaram. 

ênfase na comunicação. Seguindo a brava exortação que nos deixou o professor Magalhães Godinho - "galguem todas as fronteiras":

"Porque a grande preocupação tem sido rotular, demarcar cada qual o seu jardim. Ora o que no fundo importa são os problemas, os rótulos atrapalham mais do que esclarecem. Há, sim, que traçar com nitidez a linha divisória entre ciência e ideologia, entre teoria e doutrina. Afora essa demarcação, os grandes progressos têm-se realizado graças a convergências entre ciências inicialmente diferentes ou até opostas, por se colocarem em pontos de vista distintos. [...] Mas se um conselho se pode dar aos investigadores e pensadores que, seguindo Montaigne, pretendem «saisir l'humaine condition» - apreender a condição humana - é que esqueçam todos os rótulos e galguem todas as fronteiras" (Godinho, 2011: 26).

Ciência e ideologia, teoria e doutrina são instâncias diversas de saber e pronunciamento sobre o mundo. As influências recíprocas não derrogam a autonomia relativa. Mas a ciência também é um discurso público. 0 discurso científico, que se dirige em primeiro lugar ao interior da comunidade académica, dirige-se e deve dirigir-se, de forma derivada, adaptada às características e interesses dos diferentes auditórios, ao público às instituições, aos grupos sociais. Por maioria de razão no caso das ciências sociais e humanas, necessariamente presentes, queiram ou não os seus cultores mais rigoristas, no espaço público - e que, portanto, devem refletir sobre essa presença e estruturá-la com cuidado e temperança. Lembra-se o leitor ou leitora do célebre dito de Hamlet a Horácio: "Há mais coisas no céu e na terra do que sonha a tua filosofia"? Pois aplique-o também à ciência social. 0 "real" é sempre muito mais complexo, muito mais multifacetado, muito mais dinâmico do que pode apreender o conhecimento, por mais armas que providencie o seu arsenal teórico e técnico. A abstração indispensável ao trabalho científico significa sempre seleção, isto é, escolha, partição, iluminação disto e apagamento daquilo (daí os "tipos ideais" de Max Weber). E a consciência de tal limite implica a assunção da necessidade de empreender constantemente novas abordagens, novas aproximações ao real que buscamos conhecer.

m segundo lugar, uma atitude de humildade intelectual. Incompletude e relatividade dos saberes - não apenas (primeiro princípio) porque a realidade está sempre para além do que em cada momento sabemos dela, mas também (esta atitude) porque o saber é sempre tentativo, a sua matriz é a conjetura. Por mais sólida que pareça, uma teoria representa sempre, no seu melhor, nada mais do que um corpo de hipóteses para orientar indagações futuras e para ser escrutinado em indagações futuras.

E, finalmente, uma disposição para entender e valorizar a cultura humanista. Isso que faz que continue a ter sentido, a meu ver, falar de ciências sociais como ciências humanas: ciências sociais $e$ humanas. Humanismo, o humanismo enriquecido pela cultura e a prática científica, quer dizer convicção em duas possibilidades: a possibilidade de esclarecer questões através do conhecimento das múltiplas e diversas criações humanas no espaço e no tempo; e a possibilidade de assim contribuir para um debate público, crítico, organizado e construtivo.

Forum Sociológico, 23 | 2013 
74 Já ninguém poderá hoje reclamar o papel de um Montaigne, capaz de abarcar, numa visão de largo espectro, o amplíssimo horizonte dos problemas que definem uma condição humana. Eu, pelo menos, temo profundamente os arautos recorrentes de um ensaísmo pronto para todas as estações, feito de impressões, arrojos e figuras de estilo que disfarçam mal o mais precário e incerto senso comum. Mas, esquecendo rótulos e galgando fronteiras, não por pulsão de moda mas na senda de problemas, poderemos aspirar a uma rotina de trabalho conjunto das ciências sociais e da cultura humanística, capaz de ser ele, esse trabalho conjunto, o nosso Montaigne de agora - um olhar de grande envergadura sobre os homens e as mulheres, esses que somos, sendo ao mesmo tempo nós-sujeito e nós-objeto do conhecimento que tentamos construir.

\section{BIBLIOGRAFIA}

GEERTZ, C. ([1973] 1978), A Interpretação das Culturas, Rio de Janeiro, Zahar.

GEERTZ, C. (1983), Local Knowledge, Nova Iorque, Basic Books.

GODINHO, V. M. (1981), As Ciências Humanas: Ensino Superior e Investigação Científica em Portugal, Lisboa, Sociedade Portuguesa de Ciências Sociais e Humanas.

GODINHO, V. M. (2011), Problematizar a Sociedade, Lisboa, Quetzal.

PIRES, R. P. (2007), “Árvores conceptuais: uma reconstrução multidimensional dos conceitos de acção e de estrutura", Sociologia, Problemas e Práticas, 53: 11-50.

SANTOS, B. S. (1988), “Uma cartografia simbólica das representações sociais”, Revista Crítica de Ciências Sociais, 24: 139-172.

SILVA, A. S. (1988), Entre a Razão e o Sentido: Durkheim, Weber e a Teoria das Ciências Sociais, Porto, Afrontamento.

SILVA, A. S. (1994), Tempos Cruzados: Um Estudo Interpretativo da Cultura Popular, Porto, Afrontamento.

\section{AUTOR}

\section{AUGUSTO SANTOS SILVA}

Faculdade de Economia da Universidade do Porto (asilva@fep.up.pt) 